\title{
Administration Supervision Research on Business Information Service
}

\author{
Hai -Qi FENG ${ }^{1, a}$, Hang YIN ${ }^{2, b}$ \\ ${ }^{1,2}$ No.32th of South College Road, Beijing 100081, China \\ ahq_feng@126.com, byinhang_cufe@126.com
}

Keywords: Business information service, Administration supervision, E-commerce.

\begin{abstract}
Business information service rose fast in recent years with the growth of internet commodity. The information consumption market structure is rapidly forming, but the disorderliness and illegal information is also emerging in Business Information market and need to be solved urgently. In order to achieve a better supervision effect, this theory analyzed the supervision problem, profit Service model, current supervision laws in business information service through investigation and visiting. Thus, proposed some supervision advices to solve these supervision problems.
\end{abstract}

\section{Introduction}

China State Administration for Industry and Commerce issued "Opinions on Promoting the Development of the Network Service Transaction and Trading Rules Regulations" on notice for public comment on November 10, 2015. Network services transaction include business information service, life information service, tourism service and professional service. The most important service among which is business information service. It is embracing a rapid growth in China, but its disorderliness and illegal information problem is also serious.

Western countries standardize the market order of business information services mainly rely on industry self-regulation. In contrast, China regulate the market order through our Industrial and Commercial Administrative Department. At present, Chinese legal documents of regulations based primarily on the "Network Transaction Management Approach" (China State Administration for Industry and Commerce Order No. 60) and the "Industrial and Commercial Administrative Department Approach to Consumer Complaints"(China State Administration for Industry and Commerce Order No. 62).

To solve the supervision problems, we investigated the operators and customers in business information service industry, and visited some stuffs in Beijing Administration for Industrial and Commerce to acquire a deep understanding of the current situation and the real problem in third-party platform. Thus, proposed some regulatory proposals to supervise the business information service better.

\section{Problems of Business Information Service}

China Electronic Commerce Research Center's data show that the number of complaints in the first half of 2015 grew 2.03\% compared with the second half of 2014 in Third-party Business information service platform. These complaints are mainly about false information, counterfeiting, trademark infringement and unfair competition issues. Fig. 1 reflects the Business Information Complaints between the second half of 2014 and the first half of 2015. It shows that complaints are focused on the amount in the range of 100-500 Yuan, accounting for 41.85\% of the total complaints. The amount of loss which is less than 5,000 Yuan accounted for 91.06\% of 
total complaints. It indicates that the amounts of losses caused by illegal information in Business information service is relatively small. What's more, current judicial settlement in business information service is too complicate, the cost of complaints is overweight the cost of loss to some extent. It is exactly the small amounts and the complicate process for complaints that make the consumers tend to ignore it and are reluctant to resort to judicial settlement.

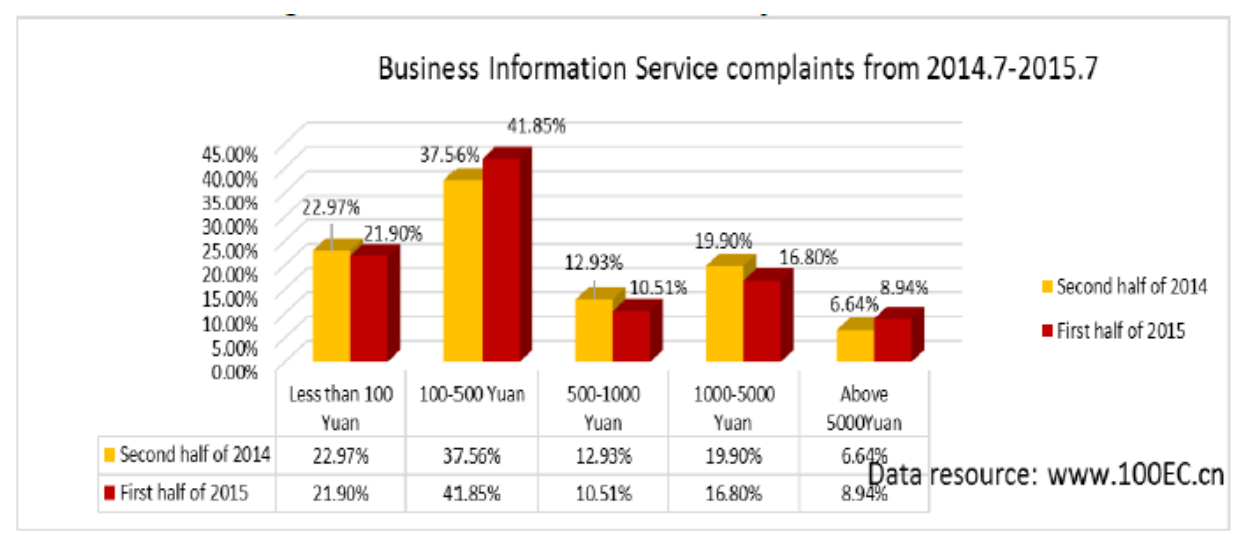

Fig.1 business information service complaints from 2014.7-2015.7.

\section{Current Regulatory Status and the Inadequacies in Business Information Service}

The current laws that China State Administration for Industry and Commerce can implement independently are "Advertising Law", "Consumer Protection Law", "Corporation Law", "Anti-Unfair Competition Law", "Trademark Law", "Contract Law", "Product Quality Law", "Electronic Signature Law" and "Tort Liability Law". Administrative regulations that can be implemented independently are "Network Transaction Management Approach" and "Industrial and Commercial Administrative Departments to Deal with Consumer Complaints Approach". In addition, the "Red Shield Network" that Administrative Department for Industry and Commerce already established recorded some operating data of business information service operators. It provides a platform for consumer's queries. Meanwhile, the Administration for Industry and Commerce Departments in some areas also implemented network inspection mechanism to regulate network transactions. These mechanisms to some extent laid the foundation for the strategy of "Network Management Network". However, current supervisions still encounter following difficulties:

The first difficulty is evidence collection for business information service transactions. Business information services platform provides an information publishing site for both information trading parties. Real transactions often happens offline or through other channels, which make transaction records difficult to obtain. In addition, the transaction process time is flexible. It exceeds the limit of daily working hours and occurs at any time. What's more, Business information services lack of a fixed market trading entity carrier and its business scope across different region, including different cities or provinces. The address provided by operators is not always true, some transactions even involving cross-border trade. These features increase the difficulty for the acquirement of forensics evidence of illegal business information.

The second difficulty is the lag of laws. Laws are the foundation for the enactment of administrative regulations. The law that China State Administration for Industry and Commerce Department currently abide by is out of date to some extent. Thus, it's difficult to form the targeted administrative regulations. Take the unfair competition of Business information service 
as an example, the "Anti-Unfair Competition Law" passed by NPC is aimed at the traditional commercial competition, the prohibition include counterfeit trademark, steal the trade secrets. But as for the click farming, a new approach for E-commerce competition, the "Anti-Unfair Competition Law" didn't define clearly.

The third difficulty is the weak real-name verification issues. Current real-name verification in business information service industry is alternative rather than a must. Take the HC INC. as an example which is one of the most famous business information service operator in China. Registration in the website is simple, as long as you can provide a user name, password, corporation name and an available cellphone number, you can successfully pass the registration process and publish your goods. Your real identity is not verified indeed.

The fourth difficulty is protecting the consumer rights with a cross-region situation. Business information services have a stronger geographical attributes, the "Network Transaction Management Approach" regulate the responsibility of the Administration for Industrial and Commerce Department. The county level department or above department of Administration for Industry and Commerce is the main supervisor for business information services and is responsible for the complaints of that county or region. However, business information service transaction often involved in cross-region trading. If the complaints occurred, consumers have to resort to the Administration for Industrial and Commerce Department which is situated in the shopkeeper's place or the third-party business information service platform's place. Currently, third-party business information service platforms have provided some complaints channels for consumers, but third party platform is neither the regulatory authorities nor the judicial administrative departments. They can't take administrative sanctions to law offenders. Feasible measures they can adopt is freezing or shutting down the account of the illegal information publisher in the third-party business information service system. This situation leads to low illegal costs for law offenders.

\section{Profit Model for Business Information Service}

The profit sources for third-party business information service can be divided into three types:

The first profit type is Membership fee. Membership fee equivalent to the registration fee, if shopkeepers need to post their information with a higher priority or get a higher credit certification, they have to pay the membership fee. Take 58 cities as an example, the revenue of membership fee in the fourth quarter of 2014 reached \$ 39.8 million, increased 53\% than the last year and equivalent to $49.6 \%$ of the total operating revenue.

The second profit type is advertising services and information services charges. Many information services published in third-party platforms are free of charge, but some specific advertising is charged by Pay-per-click effect. 58 City company gain \$ 40.3 million in this business, an increase of 113.2 percent, accounting for $30.2 \%$ of the total revenue.

The third profit type is regional franchise fee. Business information services have strong geographical characteristics. The Third-party business information service platform site is often divided by region, these partitioned areas can be contracted to a third party for operation and management. The third party business company will pay the regional franchise fee accordingly.

All of these revenues are depend on the numbers of users in Third-party platform. The size of the registered users and user habits is the key to gain profits for third-party platform companies. In order to obtain more users, Third-party platforms, on the one hand, have to promote the user experience in the website. On the other hand, third-party platform companies also tend to reduce the threshold of information posting or simplify the certification process of registration. These 
kinds of strategies lead to deteriorating for information quality and enhance the illegal information rate to some extent.

\section{Questionnaire and Survey for Business Information Service}

To investigate the situation of supervision, we distributed 180 copies of questionnaire for information consumers and visited some stuffs of China State Administration for Industrial and Commerce and Third-party platforms.

\section{Questionnaire Design and the Feedback}

Questions covered singular choice and multiple choices. These questions aimed at information consumers, with sample groups of different ages and education levels. From January 2016 to February 2016, 180 copies of questionnaires were sent altogether, 165 copies were collected, response rate was $91.7 \%$. The valid questionnaire number is 157 , the effective rate is $95.1 \%$.

\section{Reliability Analysis and Validity Analysis of the Questionnaire}

Common used reliability analysis methods are replicas reliability analysis, test-retest reliability analysis, split half reliability analysis and Cronbach Alpha reliability analysis method etc. This paper will use Cronbach $\alpha$ coefficient to test the reliability. In general, if the reliability value is higher than 0.5 in exploratory experiments, the data is suitable for factor analyze. We import our data into SPSS, analyzing results show that the "Network Information Service Administrative Supervision Consumer Survey" in Cronbach $\alpha$ coefficient was 0.786, which means high consistency of the questionnaire. Bartlett spherical testing results are shown in Table 1:

Table 1: Bartlett spherical test

KMO and Bartlett's Test

\begin{tabular}{|c|c|c|}
\hline \multicolumn{2}{|c|}{ Kaiser-Meyer-Olkin Measure of Sampling Adequacy. } & .637 \\
\hline $\begin{array}{l}\text { Bartlett's Test of } \\
\text { Sphericity }\end{array}$ & $\begin{array}{l}\text { Approx. Chi-Square } \\
\text { df } \\
\text { Sig. }\end{array}$ & $\begin{array}{r}361.672 \\
45 \\
.000\end{array}$ \\
\hline
\end{tabular}

Bartlett spherical test results indicate that KMO value is 0.637 , sig value is lower than 0.05 . The testing results show that the data collected is suitable for factor analysis. Component matrix as shown in Table 2: 
Table 2: Component matrix

\begin{tabular}{|l|r|r|r|}
\hline & \multicolumn{3}{|l|}{ Component } \\
\cline { 2 - 4 } & 0.782 & -0.502 & 3 \\
\hline Question 4 & 0.741 & -0.236 & 0.075 \\
\hline Question 5 & 0.769 & -0.463 & 0.014 \\
\hline Question 8 & 0.238 & 0.209 & -0.073 \\
\hline Question 11 & 0.374 & 0.297 & 0.570 \\
\hline Question 12 & 0.331 & 0.143 & 0.298 \\
\hline Question 13 & 0.123 & 0.197 & 0.523 \\
\hline Question 14 & 0.586 & 0.604 & -0.550 \\
\hline Question 20 & 0.523 & 0.619 & -0.269 \\
\hline Question 22 & 0.075 & 0.185 & -0.218 \\
\hline Question 26 & & & 0.302 \\
\hline
\end{tabular}

The component matrix data displayed that the first main factor has the large load in Question 4, Questions 5 and Question 8. The second main factor has the large load in question 20 and question 22. The third main factor has the large load in question 11, question 13 and question 14. The first main factor can be called as credibility factor, because the load it contains has a strong relationship with credit. Accordingly, the second main factor can be called as price factor and the third main factor can be call as quality factor. Thus, reputation, price advantages and quality of business information service is the key to attract consumers according to the above analysis. At the same time, the survey results indicate that $63.3 \%$ of the respondents said that third-party platform's irregularities have caused serious impact on its reputation and information quality. These risks will affect the future development of the business information service industry and need to take supervision measures urgently.

\section{Recommendations for Administrative Supervision of Business Information Services}

The main regulations of business information service industry are "Network transaction management approach" and "industrial and commercial administrative department approach to consumer complaints". With the Business information service industry's fast booming, supervision measures of these regulations are lagging behind. In addition, to attract more information consumers in the platform, third-party business information service corporations are reluctant to strengthen verification procedures. What's more, the high degree of difficulty for evidence collection, the hysteresis of laws and the complicated cross-region complaints are the obstacles for supervision and the healthy development of business information service industry. Thus, we proposed the following advices:

Firstly, accelerate the use of electronic documents. Electronic documents include electronic signature, electronic invoice and electronic purchase voucher etc. The "Electronic Signature Law" amended in April 24, 2015 established the legal effect of electronic signature in the form of legislation. But the legal effect of electronic invoice, electronic purchase voucher is not clearly defined. Electronic invoice is not a must for shopkeepers to provide. Thus, speed up the legislation process for electronic invoice and electronic voucher is in urgent need, so that it can give electronic invoice and electronic purchase voucher corresponding legal effect, and facilitate the acquisition of evidence for future legal proceedings.

Secondly, speed up the legislation process of relevant laws for business information services. Current laws that China State Administration for Industry and Commerce can implement 
independently are lacking clear provisions for business information service. In contrast, the service content and profit model of business information service is updating constantly. Thus, current laws are lagging behind apparently. However, enacting administrative regulations is dependent heavily on relative laws, regulations that beyond laws are not allowed. This situation exert some obstacles for enacting administrative regulations. Therefore, it is necessary to increase some relevant sections for business information service in those laws or to enact a new law for e-commerce transactions.

Thirdly, promote the combination of real-name verification and credit evaluation. This action is aimed at strengthen verification effect and reduce user loss rate from the platform. "Network Transaction Management Approach" to the provision of real-name system is not rigorous. It caused some false real-name verification that one pass the real-name system easily by using a fake name. But, strict real-name verification means too much verification process which will degrade the user experience. Therefore, it is recommended that real-name verification and credit evaluation be combined together. The strict real-name verification program can be imported as an alternative means in Business information service platform. Users who are passed real-name verification will get higher Credit rating.

Fourthly, Introduce online mediation mechanism in business information service industry. Business information service is often cross-region. Administrative departments supervise the area according to the county, which means one can't complaint over the illegal business conduction of business information service to the local Administrative Department for Industry and Commerce. One has to resort to the Administrative Department for Industry and Commerce in the shopkeeper's place or the Third-party's registration place. If online mediation mechanism is introduced, consumers can complaint the illegal business online, judicial department can collect evidence online and trial online.

Fifthly, implement "Network Patrolling" mechanism. To regulate online speech, Shenzhen used to adopt "Internet Police Patrol" mechanism, through which supervisors can patrol the whole platform to detect illegal information previously and internet users will receive hint for potential risks. This mechanism, on the one hand, can warn perpetrator in Business information service platforms. On the other hand, it can protect consumers' legal rights and mediate disputes timely.

Sixthly, implement "fraud Alliance" program for business information service operators. "Fraud Alliance" is a special rectification program first launched by 58 City Inc. It recruit volunteers from 58 City's members. Volunteers are responsible to find the illegal fraud information, and their report will receive a higher priority in processing by 58 City's antifraud department. Effective report submitted by volunteers will be treated seriously and volunteers will also receive corresponding awards. The purpose of this program is to combat illegal information in third-party business information service platform and reduce the cost of illegal information management.

Seventhly, implement intervene mechanism of administrative department. Administration for Industry and Commerce has to check the authenticity of the information transaction in business information service platform randomly. For shopkeepers that are irregular have to receive correspond warning. As for shopkeepers that breach regulation seriously, their name will be list in a black list system to remind consumers that these shopkeepers has a low reputation, transaction with them should be in caution.

\section{References}


[1] Yufeng Li. Legal research in respect of the regulation of internet advertisement, D. East China University of Political Science and Law, Shanghai, 2006.

[2] Fan, Liu. Research on Models and Strategies of Advertising Regulation: Based on the Public Interest, D. Huazhong University of Science and Technology, Wuhan, 2006.

[3] Weian Li, Shengde Wu. Reputation mechanism of online transactions, J. Nankai Business Review. 2007,(5):36-46.

[4] Bass F M. Comments on “a new product growth for model consumer durables” the bass model J. Management Science, 2004, 50(12):1833-1840.

[5] Jensen, M.C., Murphy, K.J. Performance pay and top-management incentives J. The Journal of Political Economy, 1990, 98(2):225-264.

[6] Qiang Bi, Haiyan Shi. Analysis of Current Situation in Network Information Service J. Information Science, 2003, 21(5): 452-454. 